\title{
Linear ubiquitination at a glance
}

\author{
Maureen Spit*, Eva Rieser* and Henning Walczak ${ }^{\ddagger}$
}

\section{ABSTRACT}

Ubiquitination (also known as ubiquitylation) is a post-translational modification that creates versatility in cell signalling and regulates a multitude of cellular processes. Its versatility lies in the capacity to form eight different inter-ubiquitin linkages through the seven lysine residues of ubiquitin and through its $\mathrm{N}$-terminal methionine (M1). The latter, referred to as linear or M1 linkage, is created by the linear

Centre for Cell Death, Cancer, and Inflammation (CCCI), UCL Cancer Institute, University College London, 72 Huntley Street, London WC1E 6DD, UK.

${ }^{*}$ These authors contributed equally to this work

‡Author for correspondence (h.walczak@ucl.ac.uk)

(D) M.S., 0000-0002-8593-0447; H.W., 0000-0002-6312-4591 ubiquitin chain assembly complex (LUBAC), the only E3 ligase known to date that is capable of forming linear ubiquitin chains de novo. Linear ubiquitin chains are crucial modulators of innate and adaptive immune responses, and act by regulating inflammatory and cell death signalling. In this Cell Science at a Glance article and the accompanying poster, we review the current knowledge on the role of LUBAC and linear ubiquitination in immune signalling and human physiology. We specifically focus on the role for LUBAC in signalling that is induced by the cytokine tumour necrosis factor (TNF) and its role in inflammation, gene activation and cell death. Furthermore, we highlight the roles of deubiquitinases (DUBs) that cleave M1 linkages and add an additional layer in the control of LUBAC-mediated immune signalling.

KEY WORDS: LUBAC, TNF signalling, Linear ubiquitin

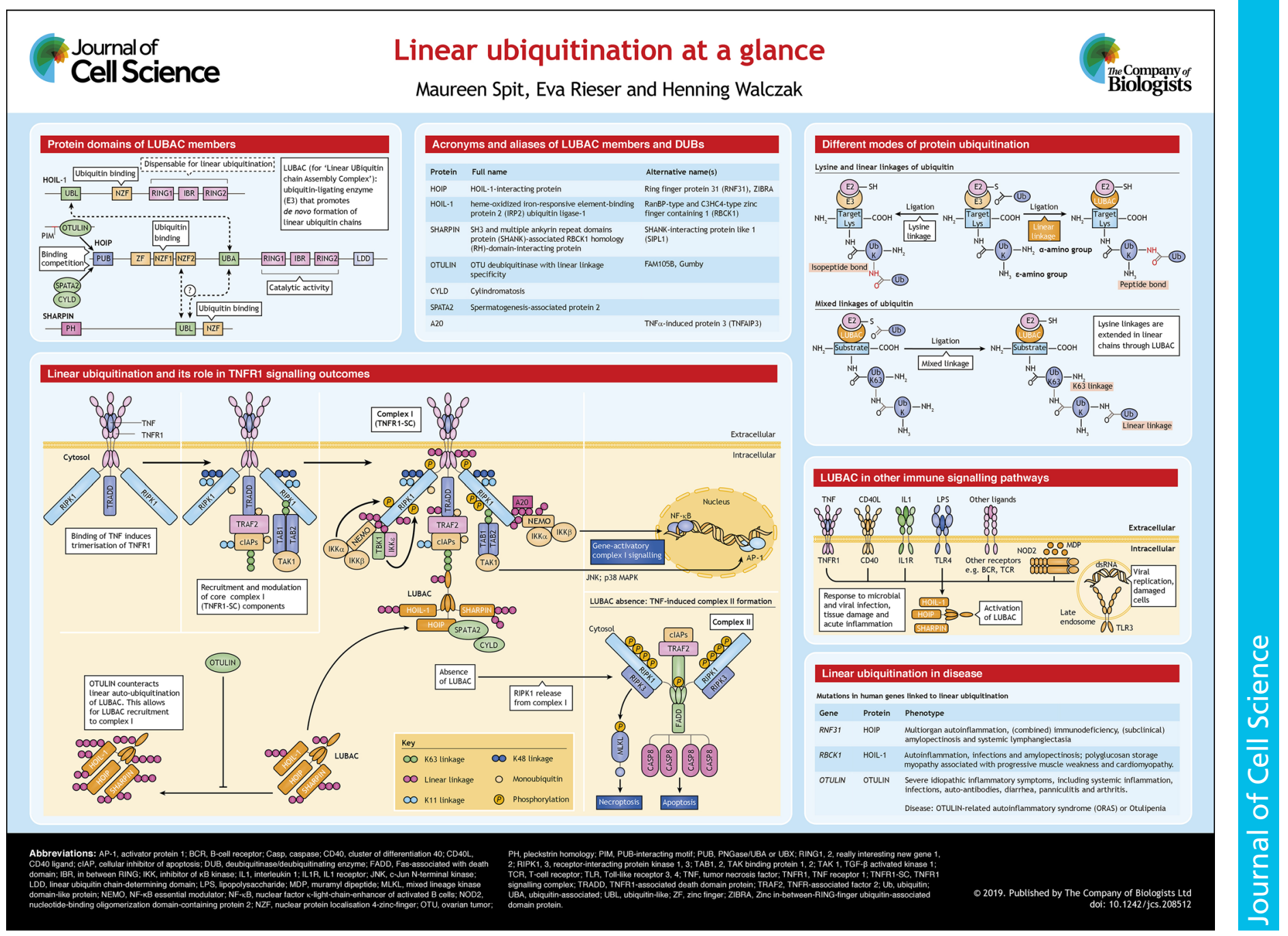




\section{Introduction}

Post-translational modifications of proteins enable and regulate cellular processes and physiological responses in a rapid and versatile manner. Ubiquitination is one of the most common posttranslational modifications. It is both inducible and reversible and is involved in controlling and fine-tuning countless signalling cascades (Komander and Rape, 2012). Ubiquitination is characterised by covalent attachment of ubiquitin to a target protein. Attachment of a single ubiquitin to a substrate is called monoubiquitination. Polyubiquitin chains are the result of an elongation process in which substrate-attached ubiquitin itself serves as the substrate. Two ubiquitin proteins can be conjugated through the C-terminus of the incoming ubiquitin and one of the seven lysine residues (K6, K11, K29, K33, K48 and K63) or, alternatively, the N-terminal methionine residue (M1) of the 'substrate' ubiquitin (Komander and Rape, 2012). Here, we focus on M1-linked ubiquitination, also called linear ubiquitination, and the linear ubiquitin chain assembly complex (LUBAC), the only known E3 ubiquitin-ligating enzyme producing M1 ubiquitin linkages de novo. LUBAC and linear ubiquitination were first described to be relevant in tumour necrosis factor (TNF) signalling (Haas et al., 2009; Tokunaga et al., 2009). We will explain the contribution of LUBAC to the formation of the TNF receptor 1 (TNFR1, also known as TNFRSF1A) signalling complex (TNFR1-SC) and how it affects the outcome of TNFR1 stimulation functionally. Proper de-ubiquitination is as important as ubiquitination itself for a physiologically balanced outcome. The three DUBs that play a role in TNF signalling are OTU deubiquitinase with linear linkage specificity (OTULIN), cylindromatosis (CYLD) and A20 (also known as TNFAIP3), and we will discuss their individual roles with respect to LUBAC and linear ubiquitination. In addition, dysregulation of M1 ubiquitination is linked to a number of severe pathologies, and we will highlight the importance of proper control of linear ubiquitination in this context.

\section{Composition and protein domains of LUBAC}

LUBAC was first described in 2006 (Kirisako et al., 2006). It consists of three subunits: HOIL-1-interacting protein (HOIP, also known as RNF31), heme-oxidized iron-responsive elementbinding protein 2 ubiquitin ligase-1 (HOIL-1, also known as RBCK1), and $\mathrm{SH} 3$ and multiple ankyrin repeat domains protein (SHANK)-associated RBCK1 homology (RH)-domaininteracting protein (SHARPIN) (Gerlach et al., 2011; Ikeda et al., 2011; Tokunaga et al., 2011). All three LUBAC components form a high-molecular-mass complex of presently unknown stoichiometry with HOIP being the only catalytically active subunit (Kirisako et al., 2006; Tokunaga et al., 2009). Proteins in the LUBAC complex harbour numerous domains, which are required for (1) formation of the complex, (2) its activity, (3) regulation of LUBAC and (4) interaction with other proteins (see poster).

\section{Formation of the complex}

The ubiquitin-like (UBL) domains of SHARPIN and HOIL-1 have both been shown to bind to HOIP, the central component of LUBAC. The interaction of the HOIL-1 UBL domain with the ubiquitin-associated (UBA) domain of HOIP is well described (Yagi et al., 2012), but the binding partner of the UBL domain of SHARPIN in HOIP is still unclear: the UBA, as well as the second nuclear protein localisation 4 (Np14)-zinc-finger (NZF2) domain in HOIP have been suggested to bind to the UBL domain of
SHARPIN (Gerlach et al., 2011; Ikeda et al., 2011; Tokunaga et al., 2011).

\section{Activity of LUBAC}

The catalytic activity of LUBAC is provided by the RING-in between RING-RING (RBR) domain in the C-terminus of HOIP plus an extension that is referred to as the linear ubiquitin chaindetermining domain (LDD) (Gerlach et al., 2011; Kirisako et al., 2006; Smit et al., 2012; Stieglitz et al., 2012, 2013; Tokunaga et al., 2011). Interestingly, HOIL-1 also has an RBR domain; it is, however, dispensable for the generation of linear ubiquitin chains by LUBAC (Kirisako et al., 2006).

\section{Regulation of LUBAC}

The PNGase/UBA or UBX (PUB) domain in HOIP associates with two different proteins: OTULIN and spermatogenesis-associated protein 2 (SPATA2) (Draber et al., 2015; Elliott et al., 2016, 2014; Kupka et al., 2016a; Rivkin et al., 2013; Schaeffer et al., 2014; Schlicher et al., 2016; Takiuchi et al., 2014; Wagner et al., 2016). Both proteins compete for binding to the PUB domain of HOIP and are important regulators of LUBAC activity.

All three LUBAC components also contain ubiquitin-binding domains (UBDs).

\section{Interaction of LUBAC with other proteins}

The NZF1 domain of HOIP, as well as the respective NZF domains of HOIL-1 and SHARPIN show ubiquitin-binding capacity of varying specificity (Haas et al., 2009; Ikeda et al., 2011; Sato et al., 2011). The contribution of these different UBDs to the stability, localisation and/or regulation of LUBAC as a consequence of its binding to different types of polyubiquitin chains is still unclear.

\section{Linear versus lysine-linked ubiquitination}

The process of ubiquitination is a multi-stage catalytic cascade, which requires the concerted action of three different classes of enzymes (Pickart and Eddins, 2004). The process is initiated by the ubiquitin-activating enzyme, also known as E1. This ATPdependent step is followed by the second step, which includes the transfer of the now activated ubiquitin from E1 to the second ubiquitin-conjugating enzyme (E2). The final step of the ubiquitination cascade requires a ubiquitin-ligating enzyme (E3), which catalyses the covalent attachment of the ubiquitin to its substrate. This usually forms an isopeptide bond between the $\varepsilon$ amino group of a lysine residue within the substrate and the carboxyl group of the C-terminus of ubiquitin (Hershko and Ciechanover, 1998) (see poster). Often, monoubiquitination of a substrate is followed by ubiquitin chain elongation (Komander and Rape, 2012). Elongation through M1 ubiquitin linkages is unique in that true peptide bonds are formed, as opposed to isopeptide bonds, which are typical for all other inter-ubiquitin linkages (Kirisako et al., 2006; Rieser et al., 2013). These bonds result from conjugation of the C-terminal carboxyl group of the incoming ubiquitin with the $\alpha$-amino group of the N-terminal methionine (M1) of the substrateattached ubiquitin, rather than with an $\varepsilon$-amino group of one of its lysine residues (Kirisako et al., 2006) (see poster). Initially, HOIP was thought to recognise target proteins directly and to catalyse their monoubiquitination and the subsequent elongation (Fujita et al., 2014; Smit et al., 2013; Tokunaga et al., 2009). Recently, an alternative model was proposed in which target proteins are first modified with K63-linked ubiquitin chains that are subsequently extended through M1 linkages by LUBAC, thereby generating mixed inter-ubiquitin linked chains (Emmerich et al., 2013). 


\section{The role of LUBAC in TNF signalling}

TNF is a proinflammatory cytokine and a major regulator of immune cells (Brenner et al., 2015). Binding of TNF to its receptor TNFR1 results in the formation of a multiprotein complex across the cell membrane, which activates a number of signalling cascades that together trigger inflammation (Kupka et al., 2016b). LUBAC is crucial for proper TNF signalling and its recruitment to the TNFR1$\mathrm{SC}$ results in M1 ubiquitination of different components of this protein complex (Shimizu et al., 2015). This enables, on the one hand, triggering of gene activation through nuclear factor $\kappa$-lightchain-enhancer of activated B cells $(\mathrm{NF}-\kappa \mathrm{B})$ and mitogen-activated protein kinases (MAPKs) leading to upregulation of a plethora of pro-survival and inflammatory genes, and, on the other hand, prevention of cell death (Emmerich et al., 2013; Gerlach et al., 2011; Haas et al., 2009; Ikeda et al., 2011; Kirisako et al., 2006; Tokunaga et al., 2009) (see poster). Formation of the TNFR1-SC, also known as complex I, is initiated by binding of TNF to TNFR1. This leads to receptor trimerisation and recruitment of the protein TNFR1associated death domain (TRADD) and the receptor-interacting serine/threonine-protein kinase 1 (RIPK1) to the intracellular death domain of the receptors (Hsu et al., 1996, 1995). TNFR1-bound TRADD serves as the adaptor for recruitment of TNF receptorassociated factor 2 (TRAF2), which in turn brings two E3 enzymes the cellular inhibitor of apoptosis proteins 1 and 2 (cIAP1/2, also known as DIAP1 and DIAP2, respectively) - to the complex (Rothe et al., 1995; Shu et al., 1996). Recruitment to the TNFR1-SC activates cIAPs, which attach K63-, K11- and K48-linked ubiquitin chains to several components of the complex (Dynek et al., 2010; GyrdHansen and Meier, 2010), thereby enabling LUBAC recruitment to complex I (Haas et al., 2009). TNFR1-recruited LUBAC linearly ubiquitinates several complex components including NF- $\kappa$ B essential modulator NEMO (also known as IKK $\gamma$, encoded by $I K B K G$ ), RIPK1, TRADD and TNFR1 (Draber et al., 2015; Gerlach et al., 2011; Haas et al., 2009). Acting in concert, the cIAP1/2- and the LUBAC-generated ubiquitin chains enable TNF-induced gene activation (Dynek et al., 2010; Haas et al., 2009; Tokunaga et al., 2009). The functional unit TAK1-TAB protein complex is recruited through this ubiquitination cascade; it consists of transforming growth factor- $\beta$-activated kinase 1 (TAK1, also known as MAP3K7), TAK1-binding protein 1 (TAB1) and either of the ubiquitin-binding proteins TAB2 or TAB3, which enable recruitment of this tripartite complex to K63-linked ubiquitin chains (Ea et al., 2006; Kanayama et al., 2004; Wang et al., 2001). Another functional unit that is recruited through ubiquitin chains is the IкB kinase (IKK) complex, which comprises the two inhibitor of $\kappa \mathrm{B}$ kinases $\alpha$ and $\beta$ (IKK $\alpha$ and IKK $\beta$, or IKK1 and IKK2; encoded by $C H U K$ and IKBKB, respectively) and NEMO (Zhang et al., 2000). Although it is able to interact with K63- and K11-linked ubiquitin chains, the affinity of NEMO for M1-linked chains is $\sim 100$-fold higher. It is this high affinity of NEMO towards M1 linkages that makes LUBAC such an important factor for proper gene induction (Dynek et al., 2010; Hadian et al., 2011; Laplantine et al., 2009; Rahighi et al., 2009; Wu et al., 2006). Within the TNFR1-SC, the TAK1-TAB complex activates MAPK cascades, which trigger the activation of the JUN Nterminal kinase $(\mathrm{JNK})$ and $\mathrm{p} 38$ pathways and result in activation of the transcription factor AP-1 (Song et al., 1997; Winston et al., 1997), whereas recruitment of the IKK complex to the TNFR1-SC activates IKK1/2, resulting in NF- $\kappa B$ activation (Chen et al., 1996; Devin et al., 2000).

Normally, TNF stimulation results in gene activation and not cell death (Vandenabeele et al., 2010). Under certain circumstances, however, a second TNF-induced signalling complex forms, referred to as complex II, and this complex promotes cell death induction. This can be caused by, among other reasons, cIAP inhibition or LUBAC ablation (Fotin-Mleczek et al., 2002; Gerlach et al., 2011; Peltzer et al., 2018, 2014; Vince et al., 2008). Complex II is cytosolic and forms upon release of RIPK1 from complex I (Micheau and Tschopp, 2003). A prerequisite for complex II formation is thought to be the RIPK1 deubiquitination by CYLD (O'Donnell et al., 2007, 2011; Wang et al., 2008). Whereas the mechanism of complex-I-to-complex-II transition remains largely unresolved, RIPK1 is known to be part of both complexes and to be an important player in the induction of cell death. Recent publications have shown that the phosphorylation of RIPK1 in complex I on specific sites within the protein serves as a checkpoint to prevent its activation through auto-phosphorylation, which is a prerequisite for the transition to complex II, thereby keeping the TNF signalling output pro-survival (Annibaldi and Meier, 2018). Several kinases, including the p38 MAPK pathway targets MAPKactivated protein kinase 2 (MK2, also known as MAPKAPK2) and TAK1, the canonical kinases IKK $\alpha$ and IKK $\beta$, as well as the noncanonical kinases TBK1 and inhibitor of $\kappa \mathrm{B}$ kinase $\varepsilon$ (IKK $\varepsilon$, encoded by $I K B K E$ ) all seem to contribute to RIPK1 inactivation through phosphorylation in order to prevent cell death (Dondelinger et al., 2017, 2015; Jaco et al., 2017; Lafont et al., 2018; Menon et al., 2017; Xu et al., 2018). Intriguingly, they cannot substitute for each other; if only one of these three distinct cell death checkpoints fails to operate properly, the other two checkpoints are not sufficient to prevent the RIPK1 transition to complex II (Lafont et al., 2018). Interestingly, it has been shown for TBK1 and IKKe that their recruitment largely depends on M1 ubiquitin linkages, and that their activation at complex I is mediated by NEMO; this partly explains the pro-survival property of LUBAC (Lafont et al., 2018). After dissociation from complex I, RIPK1 recruits the Fas-associated death domain protein (FADD), caspase-8, cellular FLICE-like inhibitory protein (cFLIP, also known as CFLAR), RIPK3 and mixed lineage kinase domain-like protein (MLKL) (Feoktistova et al., 2011; He et al., 2009; Oberst et al., 2011; Sun et al., 2012; Vanlangenakker et al., 2011). Complex II can induce cell death through two distinct processes: apoptosis or programmed necrosis, also known as necroptosis (Annibaldi and Meier, 2018) (see poster). The cell death mode that TNF induces depends on expression and activity of the various components that are involved in these processes. In summary, LUBAC and its activity are crucial for maintaining the balance between the gene-activatory and cell deathinducing outputs of TNF signalling through stabilisation of complex I and prevention of complex II formation.

\section{Linear ubiquitin-cleaving deubiquitinases}

To date, two DUBs have been shown to be capable of cleaving M1linked ubiquitin, OTULIN and CYLD (Keusekotten et al., 2013; Rivkin et al., 2013; Sato et al., 2015) (see poster). Both form complexes with LUBAC and are crucial for the regulation of TNFR1 signalling output (Draber et al., 2015; Kupka et al., 2016a; Schaeffer et al., 2014; Takiuchi et al., 2014). A third DUB, A20, is another major regulator of TNFR1 signalling, although it now appears that the majority of its effect in this pathway is independent of its DUB activity, but rather depends on its ability to stabilise linear ubiquitin chains (Draber et al., 2015; Tokunaga et al., 2012; Verhelst et al., 2012; Yamaguchi and Yamaguchi, 2015) (see Box 1).

\section{OTULIN}

OTULIN is the only known DUB that exclusively cleaves linear ubiquitin chains (Keusekotten et al., 2013; Rivkin et al., 2013). The 


\section{Box 1. The DUB A20 regulates linear ubiquitin during TNFR1 signalling}

A20 contains a deubiquitinating OTU domain at the $\mathrm{N}$-terminus and seven zinc-finger domains in its $\mathrm{C}$-terminus. The specificity of DUB activity of A20 and its relevance for A20 activity in TNF signalling is highly controversial. Initially, A20 was thought to serve as an NF-kB suppressor by cleaving K63-linked ubiquitin and additionally to act as an E3 ligase (Wertz et al., 2004). Subsequent studies, however, showed A20 specificity towards K11- and K48-linked ubiquitin (Evans et al., 2004; Komander and Barford, 2008; Lin et al., 2008; Mevissen et al., 2013; Ritorto et al., 2014) and suggested an indirect ubiquitin ligase activity for A20 when complexed with other E3s (Shembade et al., 2008, 2009). Several models explaining the repressive role of A20 in TNF-induced gene activation have been put forward, including targeting RIPK1 for proteasomal degradation (Wertz et al., 2004) and through deubiquitinating multiple TNFR1-SC components (Lork et al., 2017). However, emerging evidence shows that the regulatory role of A20 in TNF-induced gene activation depends on its non-catalytic functions. Zinc finger 7 of A20 binds M1-linked ubiquitin (Tokunaga et al., 2012; Verhelst et al., 2012), which is required for A20 recruitment to the TNFR1-SC (Draber et al., 2015). In doing so, A20 does not only protect M1-ubiquitin linkages from cleavage by CYLD, but also competes with other M1-ubiquitin-binding proteins, including NEMO, thereby negatively regulating NF-kB signalling (Bosanac et al., 2010; Draber et al., 2015; Verhelst et al., 2012). The non-catalytic functions of A20 in TNF signalling have been confirmed in vivo (De et al., 2014; Lu et al., 2013; Verhelst et al., 2014).

Additionally, A20 has been attributed a negative role in TNF-induced cell death (see poster). A20 zinc finger 7 mutant cells fail to prevent TNFinduced death, most likely because A20 can no longer bind to M1ubiquitin chains on components of the TNFR1-SC. This would have protected these components from CYLD-mediated hydrolysis and, consequently, the release of RIPK1 and the formation of complex II (Draber et al., 2015; Yamaguchi and Yamaguchi, 2015). Furthermore, A20 has been shown to restrict ubiquitination of RIPK3 and its binding to RIPK1, thereby protecting cells from necroptosis (Onizawa et al., 2015).

exquisite specificity of OTULIN for linear ubiquitin can be attributed to two features: (1) its high affinity to M1-linked di-ubiquitin, which is more than 100-fold higher than to the structurally similar, albeit distinct, K63-linked di-ubiquitin; (2) a process called 'substrateassisted catalysis', which improves the interaction between linear chains and the catalytic domain of OTULIN (Keusekotten et al., 2013). OTULIN is located in the cytosol and even though it constitutively interacts with HOIP through its PUB-interacting motif (PIM), it does not form part of the TNFR1-SC (Draber et al., 2015; Elliott et al., 2014; Schaeffer et al., 2014; Takiuchi et al., 2014). It was suggested that it exerts its function exclusively in the cytosol by counteracting LUBAC auto-ubiquitination (see poster). This appears to be a prerequisite for proper recruitment of LUBAC to TNFR1 and other receptor complexes, and subsequent adequate signalling output (Draber et al., 2015; Heger et al., 2018). The tight regulation of linear ubiquitin chains on LUBAC is crucial for proper signalling, as cells that harbour inactive OTULIN not only display increased levels of linear ubiquitination but are also sensitised to TNF-induced cell death (Draber et al., 2015; Heger et al., 2018). This is due to decreased formation of complex I, which in turn results in enhanced formation of the death-inducing complex II. Cells that are deficient for LUBAC components present highly similar phenotypes to those with inactive OTULIN, which suggests that the main role of OTULIN is to promote LUBAC function by suppressing its auto-ubiquitination, thereby enhancing LUBAC activity, rather than counteracting it (Draber et al., 2015; Heger et al., 2018; Peltzer et al., 2018, 2014).

\section{CYLD}

CYLD holds a crucial role in TNF signalling by regulating both gene-activatory signalling (Brummelkamp et al., 2003; Kovalenko et al., 2003; Reiley et al., 2004) and cell death-inducing signalling (Hitomi et al., 2008). The ubiquitin-specific proteases (USP) domain of CYLD dictates specificity for cleavage of M1 and K63 linkages (Komander et al., 2009; Ritorto et al., 2014; Sato et al., 2015). CYLD interacts with HOIP indirectly through SPATA2 (Elliott et al., 2016; Kupka et al., 2016a; Schlicher et al., 2016; Wagner et al., 2016). Following TNF stimulation, SPATA2 is required for CYLD recruitment to the TNFR1-SC (see poster); there, CYLD hydrolyses M1 and K63 linkages in ubiquitin chains on various substrates, including TNFR1, TRADD, RIPK1 and NEMO, which moderates TNF-induced gene activation (Draber et al., 2015; Elliott et al., 2016; Kovalenko et al., 2003; Kupka et al., 2016a). Absence of CYLD or SPATA2 renders cells resistant to TNF-induced apoptosis and necroptosis. This is due to stabilisation of complex I, leading to enhanced gene activation and subsequent production of pro-survival factors (Lork et al., 2017).

In summary, both linear ubiquitin-specific DUBs serve key roles in regulating the TNFR1 signalling output by fine-tuning levels of M1-linked ubiquitin, both at the receptor complex and in the cytosol.

\section{Linear ubiquitin in disease}

The crucial physiological roles of LUBAC and linear ubiquitin are illustrated by the discoveries of various human diseases that result from deregulated M1-linked ubiquitination. A recently identified patient with a homozygous missense mutation in the HOIPencoding RNF31 gene showed multi-organ auto-inflammation, recurrent viral and bacterial infections and other symptoms (Boisson et al., 2015). The missense mutation in RNF31 results in reduction of HOIP mRNA levels by half and barely detectable HOIP protein levels in patient-derived cells (Boisson et al., 2015). These clinical and cellular phenotypes largely overlap with phenotypes that are observed in several - but intriguingly not all - individuals with mutations in the HOIL-1-encoding RBCKI gene (see poster). One report described three patients with loss-ofexpression and loss-of-function mutations in RBCK1 (Boisson et al., 2012). These patients displayed a syndrome encompassing auto-inflammation, immunodeficiency and muscular amylopectinosis, which resulted in their premature death during infancy. Similar to what was seen with HOIP mutations, these mutations result in decreased expression of HOIL-1 and lower expression of the other LUBAC components (Boisson et al., 2012). The observed auto-inflammatory phenotype in both HOIP- and HOIL-1-deficient patients presumably results from elevated levels of necroptosis - the pro-inflammatory-regulated type of cell death (Vanden Berghe et al., 2014; Weinlich et al., 2017) - upon LUBAC deficiency.

Interestingly, not all truncating mutations in $R B C K 1$ lead to severe immune pathology, as they can also cause glycogen storage disease and, in some cases, a phenotype that consists of muscle weakness, progressive cardiomyopathy and signs of amylopectinosis, yet without immunodeficiency or hyper-inflammation (Nilsson et al., 2013; Wang et al., 2013). The pathological divergence of HOIL-1deficient patients could be explained by different mutation sites in $R B C K 1$, as most of the non-immune disease patients harbour homozygous mutations in the central or C-terminal part of HOIL-1, whereas immune disease patients have mutations affecting the N-terminus of HOIL-1 so that most functional domains are lacking. Additionally, two rare germline RNF31 single-nucleotide 
polymorphisms (SNPs) have been shown to be specifically enriched in patients with activated B-cell-like subtype of diffuse large B-cell lymphoma (ABC-DLBCL) compared to what is found in healthy individuals (Yang et al., 2014). These SNPs result in two recurrent missense mutations in HOIP, both affecting the UBA domain of HOIP. At a functional level, these missense mutations have been suggested to increase the association of HOIP with HOIL-1, which could augment the activity of LUBAC and, consequently, of NF- $\mathrm{KB}$ (Yang et al., 2014).

Furthermore, homozygous mutations in the OTULIN gene have been reported in autoimmune disease patients (Damgaard et al., 2016; Zhou et al., 2016), which led to neonatal-onset fever, skin rashes, auto-antibody production, diarrhoea, arthritis and failure to thrive. These pathologies were named OTULIN-related autoinflammatory syndrome (ORAS) (Damgaard et al., 2016) and otulipenia (Zhou et al., 2016). At the molecular level, some mutations are located near the ubiquitin-binding sites of OTULIN and abolish its catalytic activity (Damgaard et al., 2016). In addition, a frameshift mutation that introduces a premature stop codon results in undetectable OTULIN expression in patientderived fibroblasts (Zhou et al., 2016). As described above, it has now been clarified that OTULIN, rather than negatively regulating LUBAC activity, is required for it, and deficiency in LUBAC and OTULIN causes similar phenotypes and subsequent embryonic lethality in mice (Draber et al., 2015; Heger et al., 2018; Peltzer et al., 2018, 2014). In line with this, patients with OTULIN deficiencies show pathologies that closely resemble those from patients with HOIL-1 or HOIP mutations. Thus, the disease aetiology of OTULIN-deficient patients is presumably very similar to that of LUBAC-deficient patients.

In summary, the identification of patients with mutations in genes encoding LUBAC components or/and OTULIN illustrates the critical importance of the appropriate physiologically intended level of linear ubiquitination for tissue homeostasis.

Box 2. LUBAC in other immune signalling pathways

The role for LUBAC as a crucial regulator of signalling was discovered in the TNFR1 pathway and it is also the pathway in which its function is best characterised and understood. During the past years, however, LUBAC has also been found to be a decisive factor in many additional immune receptor signalling pathways that involve ubiquitination, including those triggered by Toll-like receptors (TLRs) [for example, liposaccharide (LPS)-activated TLR4 and double-stranded RNA (dsRNA)-activated TLR3 (Emmerich et al., 2013; Ikeda et al., 2011; Zak et al., 2011; Zinngrebe et al., 2016)], interleukin 1 (IL-1) (Emmerich et al., 2013; Gerlach et al., 2011; Ikeda et al., 2011; Tokunaga et al., 2009), retinoic acid-inducible gene-I (RIG-I) and RIG-I-like receptors (RLR) (Belgnaoui et al., 2012; Inn et al., 2011; Liu et al., 2013), a muramyl dipeptide (MDP)activated nucleotide-binding oligomerisation domain (NOD) (Damgaard et al., 2012; Draber et al., 2015; Fiil et al., 2013; Kupka et al., 2016a; Warner et al., 2013), cluster of differentiation 40 (CD40) (Dubois et al., 2014; Gerlach et al., 2011; Hostager et al., 2011), the TNF-related apoptosis-inducing ligand (TRAIL) (Lafont et al., 2017), inflammasomes (Douglas et al., 2015; Gurung et al., 2015; Nastase et al., 2016; Rodgers et al., 2014), CD95 (Taraborrelli et al., 2018) and, last but not least, the Tcell receptor (TCR) (Dubois et al., 2014; Redecke et al., 2016; Yang et al., 2016) (see poster). Together, these studies have established LUBAC and its linear ubiquitin-chain-forming activity as decisive for keeping the physiological balance between gene activation and cell death in immune receptor signalling and, thereby, as crucial regulators of innate and adaptive immunity.

\section{Conclusions and perspectives}

It is now widely recognised that linear ubiquitination is a crucial regulator of the majority of immune signalling pathways and the list of pathways that employ LUBAC-driven ubiquitination in their signalling is growing (see Box 2). Studies on LUBAC and M1linked ubiquitin have revealed its importance at the functional level in cellular systems, and at the physiological and pathological level by studying LUBAC components, and the lack thereof in vivo in mice and men. However, despite the considerable gain in knowledge over the past decade, we are far from a comprehensive understanding of the role of LUBAC in cell signalling. It now appears that we have merely broken sweat on what has turned out to be a marathon rather than a sprint: the intent to crack the (linear) ubiquitin code of immune signalling.

\section{Competing interests}

The authors declare no competing or financial interests.

\section{Funding}

This work was supported by a Wellcome Trust Investigator Award (096831/Z/11/Z), an European Research Council (ERC) Advanced Grant (294880) and a Cancer Research UK programme grant (A17341) awarded to H.W., and a Dutch Cancer Society (KWF) fellowship (BUIT 2015-7526) awarded to M.S.

\section{Cell science at a glance}

A high-resolution version of the poster and individual poster panels are available for downloading at http://jcs.biologists.org/lookup/doi/10.1242/jcs.208512.supplemental

\section{References}

Annibaldi, A. and Meier, P. (2018). Checkpoints in TNF-induced cell death: implications in inflammation and cancer. Trends Mol. Med. 24, 49-65.

Belgnaoui, S. M., Paz, S., Samuel, S., Goulet, M.-L., Sun, Q., Kikkert, M., Iwai, K., Dikic, I., Hiscott, J. and Lin, R. (2012). Linear ubiquitination of NEMO negatively regulates the interferon antiviral response through disruption of the MAVS-TRAF3 complex. Cell Host Microbe. 12, 211-222.

Boisson, B., Laplantine, E., Prando, C., Giliani, S., Israelsson, E., Xu, Z., Abhyankar, A., Israël, L., Trevejo-Nunez, G., Bogunovic, D. et al. (2012). Immunodeficiency, autoinflammation and amylopectinosis in humans with inherited HOIL-1 and LUBAC deficiency. Nat. Immunol. 13, 1178-1186.

Boisson, B., Laplantine, E., Dobbs, K., Cobat, A., Tarantino, N., Hazen, M., Lidov, H. G. W., Hopkins, G., Du, L., Belkadi, A. et al. (2015). Human HOIP and LUBAC deficiency underlies autoinflammation, immunodeficiency, amylopectinosis, and lymphangiectasia. J. Exp. Med. 212, 939-951.

Bosanac, I., Wertz, I. E., Pan, B., Yu, C., Kusam, S., Lam, C., Phu, L., Phung, Q., Maurer, B., Arnott, D. et al. (2010). Ubiquitin binding to A20 ZnF4 is required for modulation of NF-kappaB signaling. Mol. Cell 40, 548-557.

Brenner, D., Blaser, H. and Mak, T. W. (2015). Regulation of tumour necrosis factor signalling: live or let die. Nat. Rev. Immunol. 15, 362-374.

Brummelkamp, T. R., Nijman, S. M. B., Dirac, A. M. G. and Bernards, R. (2003). Loss of the cylindromatosis tumour suppressor inhibits apoptosis by activating NF-kappaB. Nature 424, 797-801.

Chen, Z. J., Parent, L. and Maniatis, T. (1996). Site-specific phosphorylation of IkappaBalpha by a novel ubiquitination-dependent protein kinase activity. Cell 84 853-862.

Damgaard, R. B., Nachbur, U., Yabal, M., Wong, W. W.-L., Fiil, B. K., Kastirr, M., Rieser, E., Rickard, J. A., Bankovacki, A., Peschel, C. et al. (2012). The ubiquitin ligase XIAP recruits LUBAC for NOD2 signaling in inflammation and innate immunity. Mol. Cell 46, 746-758.

Damgaard, R. B., Walker, J. A., Marco-Casanova, P., Morgan, N. V., Titheradge, H. L., Elliott, P. R., McHale, D., Maher, E. R., McKenzie, A. N. and Komander, D. (2016). The deubiquitinase OTULIN is an essential negative regulator of inflammation and autoimmunity. Cell 166, 1215-1230 e20.

De, A., Dainichi, T., Rathinam, C. V. and Ghosh, S. (2014). The deubiquitinase activity of A20 is dispensable for NF-kappaB signaling. EMBO Rep. 15, 775-783.

Devin, A., Cook, A., Lin, Y., Rodriguez, Y., Kelliher, M. and Liu, Z. (2000). The distinct roles of TRAF2 and RIP in IKK activation by TNF-R1: TRAF2 recruits IKK to TNF-R1 while RIP mediates IKK activation. Immunity 12, 419-429.

Dondelinger, Y., Jouan-Lanhouet, S., Divert, T., Theatre, E., Bertin, J., Gough, P. J., Giansanti, P., Heck, A. J., Dejardin, E., Vandenabeele, P. et al. (2015) NF-kappaB-independent role of IKKalpha/IKKbeta in preventing RIPK1 kinasedependent apoptotic and necroptotic cell death during TNF signaling. Mol. Cell60, 63-76.

Dondelinger, Y., Delanghe, T., Rojas-Rivera, D., Priem, D., Delvaeye, T., Bruggeman, I., Van Herreweghe, F., Vandenabeele, P. and Bertrand, M. J. M. 
(2017). MK2 phosphorylation of RIPK1 regulates TNF-mediated cell death. Nat. Cell Biol. 19, 1237-1247.

Douglas, T., Champagne, C., Morizot, A., Lapointe, J.-M. and Saleh, M. (2015) The inflammatory caspases- 1 and -11 mediate the pathogenesis of dermatitis in sharpin-deficient mice. J. Immunol. 195, 2365-2373.

Draber, P., Kupka, S., Reichert, M., Draberova, H., Lafont, E., de Miguel, D., Spilgies, L., Surinova, S., Taraborrelli, L., Hartwig, T. et al. (2015). LUBACrecruited CYLD and A20 regulate gene activation and cell death by exerting opposing effects on linear ubiquitin in signaling complexes. Cell Rep 13 2258-2272.

Dubois, S. M., Alexia, C., Wu, Y., Leclair, H. M., Leveau, C., Schol, E., Fest, T., Tarte, K., Chen, Z. J., Gavard, J. et al. (2014). A catalytic-independent role for the LUBAC in NF-kappaB activation upon antigen receptor engagement and in lymphoma cells. Blood 123, 2199-2203.

Dynek, J. N., Goncharov, T., Dueber, E. C., Fedorova, A. V., Izrael-Tomasevic, A., Phu, L., Helgason, E., Fairbrother, W. J., Deshayes, K., Kirkpatrick, D. S. et al. (2010). c-IAP1 and UbcH5 promote K11-linked polyubiquitination of RIP1 in TNF signalling. EMBO J. 29, 4198-4209.

Ea, C.-K., Deng, L., Xia, Z.-P., Pineda, G. and Chen, Z. J. (2006). Activation of IKK by TNFalpha requires site-specific ubiquitination of RIP1 and polyubiquitin binding by NEMO. Mol. Cell 22, 245-257.

Elliott, P. R., Nielsen, S. V., Marco-Casanova, P., Fiil, B. K., Keusekotten, K., Mailand, N., Freund, S. M., Gyrd-Hansen, M. and Komander, D. (2014) Molecular basis and regulation of OTULIN-LUBAC interaction. Mol. Cell 54 335-348.

Elliott, P. R., Leske, D., Hrdinka, M., Bagola, K., Fiil, B. K., McLaughlin, S. H., Wagstaff, J., Volkmar, N., Christianson, J. C., Kessler, B. M. et al. (2016). SPATA2 links CYLD to LUBAC, activates CYLD, and controls LUBAC signaling. Mol. Cell 63, 990-1005

Emmerich, C. H., Ordureau, A., Strickson, S., Arthur, J. S., Pedrioli, P. G., Komander, D. and Cohen, P. (2013). Activation of the canonical IKK complex by K63/M1-linked hybrid ubiquitin chains. Proc. Natl. Acad. Sci. USA 110 $15247-15252$.

Evans, P. C., Ovaa, H., Hamon, M., Kilshaw, P. J., Hamm, S., Bauer, S., Ploegh, H. L. and Smith, T. S. (2004). Zinc-finger protein A20, a regulator of inflammation and cell survival, has de-ubiquitinating activity. Biochem. J. 378, 727-734.

Feoktistova, M., Geserick, P., Kellert, B., Dimitrova, D. P., Langlais, C., Hupe, M., Cain, K., MacFarlane, M., Hacker, G. and Leverkus, M. (2011). clAPs block Ripoptosome formation, a RIP1/caspase-8 containing intracellular cell death complex differentially regulated by cFLIP isoforms. Mol. Cell 43, 449-463.

Fiil, B. K., Damgaard, R. B., Wagner, S. A., Keusekotten, K., Fritsch, M., BekkerJensen, S., Mailand, N., Choudhary, C., Komander, D. and Gyrd-Hansen, M. (2013). OTULIN restricts Met1-linked ubiquitination to control innate immune signaling. Mol. Cell 50, 818-830.

Fotin-Mleczek, M., Henkler, F., Samel, D., Reichwein, M., Hausser, A., Parmryd, I., Scheurich, P., Schmid, J. A. and Wajant, H. (2002). Apoptotic crosstalk of TNF receptors: TNF-R2-induces depletion of TRAF2 and IAP proteins and accelerates TNF-R1-dependent activation of caspase-8. J. Cell Sci. 115, 2757-2770

Fujita, H., Rahighi, S., Akita, M., Kato, R., Sasaki, Y., Wakatsuki, S. and Iwai, K. (2014). Mechanism underlying IkappaB kinase activation mediated by the linear ubiquitin chain assembly complex. Mol. Cell. Biol. 34, 1322-1335.

Gerlach, B., Cordier, S. M., Schmukle, A. C., Emmerich, C. H., Rieser, E., Haas, T. L., Webb, A. I., Rickard, J. A., Anderton, H., Wong, W. W.-L. et al. (2011) Linear ubiquitination prevents inflammation and regulates immune signalling. Nature 471, 591-596.

Gurung, P., Lamkanfi, M. and Kanneganti, T.-D. (2015). Cutting edge: SHARPIN is required for optimal NLRP3 inflammasome activation. J. Immunol. 194 2064-2067.

Gyrd-Hansen, M. and Meier, P. (2010). IAPs: from caspase inhibitors to modulators of NF-kappaB, inflammation and cancer. Nat. Rev. Cancer 10, 561-574.

Haas, T. L., Emmerich, C. H., Gerlach, B., Schmukle, A. C., Cordier, S. M., Rieser, E., Feltham, R., Vince, J., Warnken, U., Wenger, T. et al. (2009) Recruitment of the linear ubiquitin chain assembly complex stabilizes the TNF-R1 signaling complex and is required for TNF-mediated gene induction. Mol. Cell $\mathbf{3 6}$ 831-844

Hadian, K., Griesbach, R. A., Dornauer, S., Wanger, T. M., Nagel, D., Metlitzky, M., Beisker, W., Schmidt-Supprian, M. and Krappmann, D. (2011). NF-kappaB essential modulator (NEMO) interaction with linear and lys-63 ubiquitin chains contributes to NF-kappaB activation. J. Biol. Chem. 286, 26107-26117.

He, S., Wang, L., Miao, L., Wang, T., Du, F., Zhao, L. and Wang, X. (2009) Receptor interacting protein kinase-3 determines cellular necrotic response to TNF-alpha. Cell 137, 1100-1111

Heger, K., Wickliffe, K. E., Ndoja, A., Zhang, J., Murthy, A., Dugger, D. L., Maltzman, A., de Sousa, E. M. F., Hung, J., Zeng, Y. et al. (2018). OTULIN limits cell death and inflammation by deubiquitinating LUBAC. Nature 559, 120-124.

Hershko, A. and Ciechanover, A. (1998). The ubiquitin system. Annu. Rev. Biochem. 67, 425-479.
Hitomi, J., Christofferson, D. E., Ng, A., Yao, J., Degterev, A., Xavier, R. J. and Yuan, J. (2008). Identification of a molecular signaling network that regulates a cellular necrotic cell death pathway. Cell 135, 1311-1323.

Hostager, B. S., Kashiwada, M., Colgan, J. D. and Rothman, P. B. (2011). HOIL$1 \mathrm{~L}$ interacting protein (HOIP) is essential for CD40 signaling. PLOS ONE 6, e23061

Hsu, H., Xiong, J. and Goeddel, D. V. (1995). The TNF receptor 1-associated protein TRADD signals cell death and NF-kappa B activation. Cell 81, 495-504.

Hsu, H., Huang, J., Shu, H.-B., Baichwal, V. and Goeddel, D. V. (1996). TNFdependent recruitment of the protein kinase RIP to the TNF receptor-1 signaling complex. Immunity 4, 387-396

Ikeda, F., Deribe, Y. L., Skanland, S. S., Stieglitz, B., Grabbe, C., Franz-Wachtel, M., van Wijk, S. J. L., Goswami, P., Nagy, V., Terzic, J. et al. (2011). SHARPIN forms a linear ubiquitin ligase complex regulating NF-kappaB activity and apoptosis. Nature 471, 637-641.

Inn, K.-S., Gack, M. U., Tokunaga, F., Shi, M., Wong, L.-Y., Iwai, K. and Jung, J. U. (2011). Linear ubiquitin assembly complex negatively regulates RIG-I- and TRIM25-mediated type I interferon induction. Mol. Cell 41, 354-365.

Jaco, I., Annibaldi, A., Lalaoui, N., Wilson, R., Tenev, T., Laurien, L., Kim, C., Jamal, K., Wicky John, S., Liccardi, G. et al. (2017). MK2 phosphorylates RIPK1 to prevent TNF-induced cell death. Mol. Cell 66, 698-710 e5.

Kanayama, A., Seth, R. B., Sun, L., Ea, C.-K., Hong, M., Shaito, A., Chiu, Y. H., Deng, L. and Chen, Z. J. (2004). TAB2 and TAB3 activate the NF-kappaB pathway through binding to polyubiquitin chains. Mol. Cell 15, 535-548.

Keusekotten, K., Elliott, P. R., Glockner, L., Fiil, B. K., Damgaard, R. B., Kulathu, Y., Wauer, T., Hospenthal, M. K., Gyrd-Hansen, M., Krappmann, D. et al. (2013). OTULIN antagonizes LUBAC signaling by specifically hydrolyzing Met1linked polyubiquitin. Cell 153, 1312-1326

Kirisako, T., Kamei, K., Murata, S., Kato, M., Fukumoto, H., Kanie, M., Sano, S. Tokunaga, F., Tanaka, K. and Iwai, K. (2006). A ubiquitin ligase complex assembles linear polyubiquitin chains. EMBO J. 25, 4877-4887.

Komander, D. and Barford, D. (2008). Structure of the A20 OTU domain and mechanistic insights into deubiquitination. Biochem. J. 409, 77-85.

Komander, D. and Rape, M. (2012). The ubiquitin code. Annu. Rev. Biochem. 81 203-229

Komander, D., Reyes-Turcu, F., Licchesi, J. D. F., Odenwaelder, P., Wilkinson, K. D. and Barford, D. (2009). Molecular discrimination of structurally equivalent Lys 63-linked and linear polyubiquitin chains. EMBO Rep. 10, 466-473.

Kovalenko, A., Chable-Bessia, C., Cantarella, G., Israël, A., Wallach, D. and Courtois, G. (2003). The tumour suppressor CYLD negatively regulates NFkappaB signalling by deubiquitination. Nature 424, 801-805.

Kupka, S., De Miguel, D., Draber, P., Martino, L., Surinova, S., Rittinger, K. and Walczak, H. (2016a). SPATA2-mediated binding of CYLD to HOIP enables CYLD recruitment to signaling complexes. Cell Rep 17, 31033-31036.

Kupka, S., Reichert, M., Draber, P. and Walczak, H. (2016b). Formation and removal of poly-ubiquitin chains in the regulation of tumor necrosis factor-induced gene activation and cell death. FEBS J. 283, 2626-2639.

Lafont, E., Kantari-Mimoun, C., Draber, P., De Miguel, D., Hartwig, T., Reichert, M., Kupka, S., Shimizu, Y., Taraborrelli, L., Spit, M. et al. (2017). The linea ubiquitin chain assembly complex regulates TRAIL-induced gene activation and cell death. EMBO J.. 36, 1147-1166.

Lafont, E., Draber, P., Rieser, E., Reichert, M., Kupka, S., de Miguel, D. Draberova, H., von Massenhausen, A., Bhamra, A., Henderson, S. et al. (2018). TBK1 and IKKepsilon prevent TNF-induced cell death by RIPK1 phosphorylation. Nat. Cell Biol.. 20, 1389-1399.

Laplantine, E., Fontan, E., Chiaravalli, J., Lopez, T., Lakisic, G., Véron, M. Agou, F. and Israël, A. (2009). NEMO specifically recognizes K63-linked polyubiquitin chains through a new bipartite ubiquitin-binding domain. EMBO J. 28 2885-2895.

Lin, S.-C., Chung, J. Y., Lamothe, B., Rajashankar, K., Lu, M., Lo, Y.-C., Lam, A. Y., Darnay, B. G. and Wu, H. (2008). Molecular basis for the unique deubiquitinating activity of the NF-kappaB inhibitor A20. J. Mol. Biol. 376 526-540

Liu, S., Chen, J., Cai, X., Wu, J., Chen, X., Wu, Y. T., Sun, L. and Chen, Z. J. (2013). MAVS recruits multiple ubiquitin E3 ligases to activate antiviral signaling cascades. Elife 2, e00785.

Lork, M., Verhelst, K. and Beyaert, R. (2017). CYLD, A20 and OTULIN deubiquitinases in NF-kappaB signaling and cell death: so similar, yet so different. Cell Death Differ. 24, 1172-1183.

Lu, T. T., Onizawa, M., Hammer, G. E., Turer, E. E., Yin, Q., Damko, E., Agelidis A., Shifrin, N., Advincula, R., Barrera, J. et al. (2013). Dimerization and ubiquitin mediated recruitment of A20, a complex deubiquitinating enzyme. Immunity 38 896-905.

Menon, M. B., Gropengiesser, J., Fischer, J., Novikova, L., Deuretzbacher, A. Lafera, J., Schimmeck, H., Czymmeck, N., Ronkina, N., Kotlyarov, A. et al. (2017). p38(MAPK)/MK2-dependent phosphorylation controls cytotoxic RIPK1 signalling in inflammation and infection. Nat. Cell Biol. 19, 1248-1259.

Mevissen, T. E., Hospenthal, M. K., Geurink, P. P., Elliott, P. R., Akutsu, M., Arnaudo, N., Ekkebus, R., Kulathu, Y., Wauer, T., El Oualid, F. et al. (2013). 
OTU deubiquitinases reveal mechanisms of linkage specificity and enable ubiquitin chain restriction analysis. Cell 154, 169-184

Micheau, O. and Tschopp, J. (2003). Induction of TNF receptor I-mediated apoptosis via two sequential signaling complexes. Cell 114, 181-190.

Nastase, M.-V., Zeng-Brouwers, J., Frey, H., Hsieh, L. T.-H., Poluzzi, C., Beckmann, J., Schroeder, N., Pfeilschifter, J., Lopez-Mosqueda, J., Mersmann, J. et al. (2016). An essential role for SHARPIN in the regulation of caspase 1 activity in sepsis. Am. J. Pathol. 186, 1206-1220.

Nilsson, J., Schoser, B., Laforet, P., Kalev, O., Lindberg, C., Romero, N. B. Davila Lopez, M., Akman, H. O., Wahbi, K., Iglseder, S. et al. (2013) Polyglucosan body myopathy caused by defective ubiquitin ligase RBCK1. Ann. Neurol. 74, 914-919.

Oberst, A., Dillon, C. P., Weinlich, R., McCormick, L. L., Fitzgerald, P., Pop, C. Hakem, R., Salvesen, G. S. and Green, D. R. (2011). Catalytic activity of the caspase-8-FLIP(L) complex inhibits RIPK3-dependent necrosis. Nature 471 363-367.

O'Donnell, M. A., Legarda-Addison, D., Skountzos, P., Yeh, W. C. and Ting, A. T (2007). Ubiquitination of RIP1 regulates an NF-kappaB-independent cell-death switch in TNF signaling. Curr. Biol. 17, 418-424.

O'Donnell, M. A., Perez-Jimenez, E., Oberst, A., Ng, A., Massoumi, R., Xavier, R., Green, D. R. and Ting, A. T. (2011). Caspase 8 inhibits programmed necrosis by processing CYLD. Nat. Cell Biol. 13, 1437-1442

Onizawa, M., Oshima, S., Schulze-Topphoff, U., Oses-Prieto, J. A., Lu, T., Tavares, R., Prodhomme, T., Duong, B., Whang, M. I., Advincula, R. et al. (2015). The ubiquitin-modifying enzyme A20 restricts ubiquitination of the kinase RIPK3 and protects cells from necroptosis. Nat. Immunol. 16, 618-627.

Peltzer, N., Rieser, E., Taraborrelli, L., Draber, P., Darding, M., Pernaute, B. Shimizu, Y., Sarr, A., Draberova, H., Montinaro, A. et al. (2014). HOIP deficiency causes embryonic lethality by aberrant TNFR1-mediated endothelia cell death. Cell Rep 9, 153-165.

Peltzer, N., Darding, M., Montinaro, A., Draber, P., Draberova, H., Kupka, S., Rieser, E., Fisher, A., Hutchinson, C., Taraborrelli, L. et al. (2018). LUBAC is essential for embryogenesis by preventing cell death and enabling haematopoiesis. Nature 557, 112-117.

Pickart, C. M. and Eddins, M. J. (2004). Ubiquitin: structures, functions, mechanisms. Biochim. Biophys. Acta 1695, 55-72.

Rahighi, S., Ikeda, F., Kawasaki, M., Akutsu, M., Suzuki, N., Kato, R., Kensche, T., Uejima, T., Bloor, S., Komander, D. et al. (2009). Specific recognition of linear ubiquitin chains by NEMO is important for NF-kappaB activation. Cell 136, 1098-1109.

Redecke, V., Chaturvedi, V., Kuriakose, J. and Hacker, H. (2016). SHARPIN controls the development of regulatory T cells. Immunology 148, 216-226.

Reiley, W., Zhang, M. and Sun, S.-C. (2004). Negative regulation of JNK signaling by the tumor suppressor CYLD. J. Biol. Chem. 279, 55161-55167.

Rieser, E., Cordier, S. M. and Walczak, H. (2013). Linear ubiquitination: a newly discovered regulator of cell signalling. Trends Biochem. Sci. 38, 94-102.

Ritorto, M. S., Ewan, R., Perez-Oliva, A. B., Knebel, A., Buhrlage, S. J., Wightman, M., Kelly, S. M., Wood, N. T., Virdee, S., Gray, N. S. et al. (2014) Screening of DUB activity and specificity by MALDI-TOF mass spectrometry. Nat. Commun. 5, 4763

Rivkin, E., Almeida, S. M., Ceccarelli, D. F., Juang, Y.-C., MacLean, T. A., Srikumar, T., Huang, H., Dunham, W. H., Fukumura, R., Xie, G. et al. (2013) The linear ubiquitin-specific deubiquitinase gumby regulates angiogenesis Nature 498, 318-324.

Rodgers, M. A., Bowman, J. W., Fujita, H., Orazio, N., Shi, M., Liang, Q., Amatya R., Kelly, T. J., Iwai, K., Ting, J. et al. (2014). The linear ubiquitin assembly complex (LUBAC) is essential for NLRP3 inflammasome activation. J. Exp. Med 211, 1333-1347.

Rothe, M., Pan, M.-G., Henzel, W. J., Ayres, T. M. and Goeddel, D. V. (1995). The TNFR2-TRAF signaling complex contains two novel proteins related to baculoviral inhibitor of apoptosis proteins. Cell 83, 1243-1252.

Sato, Y., Fujita, H., Yoshikawa, A., Yamashita, M., Yamagata, A., Kaiser, S. E., Iwai, K. and Fukai, S. (2011). Specific recognition of linear ubiquitin chains by the Npl4 zinc finger (NZF) domain of the HOIL-1L subunit of the linear ubiquitin chain assembly complex. Proc. Natl. Acad. Sci. USA 108, 20520-20525

Sato, Y., Goto, E., Shibata, Y., Kubota, Y., Yamagata, A., Goto-Ito, S., Kubota, K., Inoue, J., Takekawa, M., Tokunaga, F. et al. (2015). Structures of CYLD USP with Met1- or Lys63-linked diubiquitin reveal mechanisms for dual specificity. Nat. Struct. Mol. Biol. 22, 222-229.

Schaeffer, V., Akutsu, M., Olma, M. H., Gomes, L. C., Kawasaki, M. and Dikic, I. (2014). Binding of OTULIN to the PUB domain of HOIP controls NF-kappaB signaling. Mol. Cell 54, 349-361.

Schlicher, L., Wissler, M., Preiss, F., Brauns-Schubert, P., Jakob, C., Dumit, V., Borner, C., Dengjel, J. and Maurer, U. (2016). SPATA2 promotes CYLD activity and regulates TNF-induced NF-kappaB signaling and cell death. EMBO Rep. 25

Shembade, N., Harhaj, N. S., Parvatiyar, K., Copeland, N. G., Jenkins, N. A. Matesic, L. E. and Harhaj, E. W. (2008). The E3 ligase Itch negatively regulates inflammatory signaling pathways by controlling the function of the ubiquitin-editing enzyme A20. Nat. Immunol. 9, 254-262.
Shembade, N., Parvatiyar, K., Harhaj, N. S. and Harhaj, E. W. (2009). The ubiquitin-editing enzyme $A 20$ requires RNF11 to downregulate NF-kappaB signalling. EMBO J. 28, 513-522.

Shimizu, Y., Taraborrelli, L. and Walczak, H. (2015). Linear ubiquitination in immunity. Immunol. Rev. 266, 190-207.

Shu, H. B., Takeuchi, M. and Goeddel, D. V. (1996). The tumor necrosis factor receptor 2 signal transducers TRAF2 and C-IAP1 are components of the tumor necrosis factor receptor 1 signaling complex. Proc. Natl. Acad. Sci. USA 93 13973-13978.

Smit, J. J., Monteferrario, D., Noordermeer, S. M., van Dijk, W. J., van der Reijden, B. A. and Sixma, T. K. (2012). The E3 ligase HOIP specifies linear ubiquitin chain assembly through its RING-IBR-RING domain and the unique LDD extension. EMBO J. 31, 3833-3844.

Smit, J. J., van Dijk, W. J., El Atmioui, D., Merkx, R., Ovaa, H. and Sixma, T. K. (2013). Target specificity of the E3 ligase LUBAC for ubiquitin and NEMO relies on different minimal requirements. J. Biol. Chem. 288, 31728-31737.

Song, H. Y., Regnier, C. H., Kirschning, C. J., Goeddel, D. V. and Rothe, M. (1997). Tumor necrosis factor (TNF)-mediated kinase cascades: bifurcation of nuclear factor-kappaB and c-jun N-terminal kinase (JNK/SAPK) pathways at TNF receptor-associated factor 2. Proc. Natl. Acad. Sci. USA 94, 9792-9796.

Stieglitz, B., Morris-Davies, A. C., Koliopoulos, M. G., Christodoulou, E. and Rittinger, K. (2012). LUBAC synthesizes linear ubiquitin chains via a thioester intermediate. EMBO Rep. 13, 840-846.

Stieglitz, B., Rana, R. R., Koliopoulos, M. G., Morris-Davies, A. C., Schaeffer, V., Christodoulou, E., Howell, S., Brown, N. R., Dikic, I. and Rittinger, K. (2013) Structural basis for ligase-specific conjugation of linear ubiquitin chains by HOIP. Nature 503, 422-426.

Sun, L., Wang, H., Wang, Z., He, S., Chen, S., Liao, D., Wang, L., Yan, J., Liu, W., Lei, X. et al. (2012). Mixed lineage kinase domain-like protein mediates necrosis signaling downstream of RIP3 kinase. Cell 148, 213-227.

Takiuchi, T., Nakagawa, T., Tamiya, H., Fujita, H., Sasaki, Y., Saeki, Y., Takeda H., Sawasaki, T., Buchberger, A., Kimura, T. et al. (2014). Suppression of LUBAC-mediated linear ubiquitination by a specific interaction between LUBAC and the deubiquitinases CYLD and OTULIN. Genes Cells 19, 254-272.

Taraborrelli, L., Peltzer, N., Montinaro, A., Kupka, S., Rieser, E., Hartwig, T. Sarr, A., Darding, M., Draber, P., Haas, T. L. et al. (2018). LUBAC prevents lethal dermatitis by inhibiting cell death induced by TNF, TRAIL and CD95L. Nat. Commun. 9, 3910

Tokunaga, F., Sakata, S., Saeki, Y., Satomi, Y., Kirisako, T., Kamei, K. Nakagawa, T., Kato, M., Murata, S., Yamaoka, S. et al. (2009). Involvement of linear polyubiquitylation of NEMO in NF-kappaB activation. Nat. Cell Biol. 11 123-132.

Tokunaga, F., Nakagawa, T., Nakahara, M., Saeki, Y., Taniguchi, M., Sakata, S. Tanaka, K., Nakano, H. and Iwai, K. (2011). SHARPIN is a component of the NFkappaB-activating linear ubiquitin chain assembly complex. Nature 471, 633-636.

Tokunaga, F., Nishimasu, H., Ishitani, R., Goto, E., Noguchi, T., Mio, K., Kamei, K., Ma, A., Iwai, K. and Nureki, O. (2012). Specific recognition of linear polyubiquitin by $A 20$ zinc finger 7 is involved in NF-kappaB regulation. EMBO J. 31, 3856-3870

Vandenabeele, P., Declercq, W., Van Herreweghe, F. and Vanden Berghe, T. (2010). The role of the kinases RIP1 and RIP3 in TNF-induced necrosis. Sci. Signal. 3, re4.

Vanden Berghe, T., Linkermann, A., Jouan-Lanhouet, S., Walczak, H. and Vandenabeele, P. (2014). Regulated necrosis: the expanding network of nonapoptotic cell death pathways. Nat. Rev. Mol. Cell Biol. 15, 135-147.

Vanlangenakker, N., Bertrand, M. J., Bogaert, P., Vandenabeele, P. and Vanden Berghe, T. (2011). TNF-induced necroptosis in L929 cells is tightly regulated by multiple TNFR1 complex I and II members. Cell Death Dis 2, e230.

Verhelst, K., Carpentier, I., Kreike, M., Meloni, L., Verstrepen, L., Kensche, T., Dikic, I. and Beyaert, R. (2012). A20 inhibits LUBAC-mediated NF-kappaB activation by binding linear polyubiquitin chains via its zinc finger 7. EMBO J. 31 3845-3855.

Verhelst, K., van Loo, G. and Beyaert, R. (2014). A20: attractive without showing cleavage. EMBO Rep. 15, 734-735

Vince, J. E., Chau, D., Callus, B., Wong, W. W.-L., Hawkins, C. J., Schneider, P., McKinlay, M., Benetatos, C. A., Condon, S. M., Chunduru, S. K. et al. (2008) TWEAK-FN14 signaling induces lysosomal degradation of a clAP1-TRAF2 complex to sensitize tumor cells to TNFalpha. J. Cell Biol. 182, 171-184.

Wagner, S. A., Satpathy, S., Beli, P. and Choudhary, C. (2016). SPATA2 links CYLD to the TNF-alpha receptor signaling complex and modulates the recepto signaling outcomes. EMBO J. 35, 1868-1884.

Wang, C., Deng, L., Hong, M., Akkaraju, G. R., Inoue, J. and Chen, Z. J. (2001) TAK1 is a ubiquitin-dependent kinase of MKK and IKK. Nature 412, 346-351.

Wang, L., Du, F. and Wang, X. (2008). TNF-alpha induces two distinct caspase-8 activation pathways. Cell 133, 693-703.

Wang, K., Kim, C., Bradfield, J., Guo, Y., Toskala, E., Otieno, F. G., Hou, C. Thomas, K., Cardinale, C., Lyon, G. J. et al. (2013). Whole-genome DNA/RNA sequencing identifies truncating mutations in RBCK1 in a novel Mendelian disease with neuromuscular and cardiac involvement. Genome Med. 5, 67. 
Warner, N., Burberry, A., Franchi, L., Kim, Y.-G., McDonald, C., Sartor, M. A. and Nunez, G. (2013). A genome-wide siRNA screen reveals positive and negative regulators of the NOD2 and NF-kappaB signaling pathways. Sci. Signal. 6, rs3.

Weinlich, R., Oberst, A., Beere, H. M. and Green, D. R. (2017). Necroptosis in development, inflammation and disease. Nat. Rev. Mol. Cell Biol. 18, 127-136.

Wertz, I. E., O'Rourke, K. M., Zhou, H., Eby, M., Aravind, L., Seshagiri, S., Wu, P., Wiesmann, C., Baker, R., Boone, D. L. et al. (2004). De-ubiquitination and ubiquitin ligase domains of A20 downregulate NF-kappaB signalling. Nature 430, 694-699.

Winston, B. W., Chan, E. D., Johnson, G. L. and Riches, D. W. (1997). Activation of p38mapk, MKK3, and MKK4 by TNF-alpha in mouse bone marrow-derived macrophages. J. Immunol. 159, 4491-4497.

Wu, C.-J., Conze, D. B., Li, T., Srinivasula, S. M. and Ashwell, J. D. (2006) Sensing of Lys 63-linked polyubiquitination by NEMO is a key event in NF-kappaB activation [corrected]. Nat. Cell Biol. 8, 398-406.

Xu, D., Jin, T., Zhu, H., Chen, H., Ofengeim, D., Zou, C., Mifflin, L., Pan, L., Amin, P., Li, W. et al. (2018). TBK1 suppresses RIPK1-driven apoptosis and inflammation during development and in aging. Cell 174, 1477-1491 e19.

Yagi, H., Ishimoto, K., Hiromoto, T., Fujita, H., Mizushima, T., Uekusa, Y., YagiUtsumi, M., Kurimoto, E., Noda, M., Uchiyama, S. et al. (2012). A noncanonical UBA-UBL interaction forms the linear-ubiquitin-chain assembly complex. EMBO Rep. 13, 462-468.

Yamaguchi, N. and Yamaguchi, N. (2015). The seventh zinc finger motif of A20 is required for the suppression of TNF-alpha-induced apoptosis. FEBS Lett. $\mathbf{5 8 9}$ 1369-1375.
Yang, Y., Schmitz, R., Mitala, J., Whiting, A., Xiao, W., Ceribelli, M., Wright, G. W., Zhao, H., Yang, Y., Xu, W. et al. (2014). Essential role of the linear ubiquitin chain assembly complex in lymphoma revealed by rare germline polymorphisms. Cancer Discov 4, 480-493.

Yang, Y.-K., Yang, C., Chan, W., Wang, Z., Deibel, K. E. and Pomerantz, J. L. (2016). Molecular determinants of scaffold-induced linear ubiquitinylation of B cell lymphoma/leukemia 10 (Bcl10) during $\mathrm{T}$ cell receptor and oncogenic caspase recruitment domain-containing protein 11 (CARD11) signaling. J. Biol. Chem. 291, 25921-25936.

Zak, D. E., Schmitz, F., Gold, E. S., Diercks, A. H., Peschon, J. J., Valvo, J. S., Niemisto, A., Podolsky, I., Fallen, S. G., Suen, R. et al. (2011). Systems analysis identifies an essential role for SHANK-associated RH domain-interacting protein (SHARPIN) in macrophage Toll-like receptor 2 (TLR2) responses. Proc. Natl. Acad. Sci. USA 108, 11536-11541.

Zhang, S. Q., Kovalenko, A., Cantarella, G. and Wallach, D. (2000). Recruitment of the IKK signalosome to the p55 TNF receptor: RIP and A20 bind to NEMO (IKKgamma) upon receptor stimulation. Immunity 12, 301-311.

Zhou, Q., Yu, X., Demirkaya, E., Deuitch, N., Stone, D., Tsai, W. L., Kuehn, H. S., Wang, H., Yang, D., Park, Y. H. et al. (2016). Biallelic hypomorphic mutations in a linear deubiquitinase define otulipenia, an early-onset autoinflammatory disease. Proc. Natl. Acad. Sci. USA 113, 10127-10132.

Zinngrebe, J., Rieser, E., Taraborrelli, L., Peltzer, N., Hartwig, T., Ren, H. Kovács, I., Endres, C., Draber, P., Darding, M. et al. (2016). -LUBAC deficiency perturbs TLR3 signaling to cause immunodeficiency and autoinflammation. J. Exp. Med. 213, 2671-2689. 